\title{
SWCS CONFERENCE Reflections on the 2014 SWCS International ECHOES Annual Conference
}

\author{
Jim Gulliford
}

A s I look back on the four days we spent in suburban Chicago, Illinois, last month for the 69th International Annual Conference of the Soil and Water Conservation Society (SWCS), my two strongest impressions were the relevance of the program to our global conservation challenges and the diversity of our more than 400 conference attendees and the ideas they expressed. These two factors made for an exciting and thoughtful exchange of science and policy perspectives concerning our life on land and its impact on water. A heartfelt thanks goes out to Tommy Bass, program committee chair, and the entire annual conference planning team for their work to assemble a comprehensive program featuring plenaries, workshops, symposia, oral presentations, exhibits, posters, and tours; these opportunities provided an ideal forum for learning and networking.

The conference theme "Making Waves in Conservation: Our Life on Land and Its Impact on Water" suggested two strong messages. First, it emphasized the importance of understanding the science of our actions and the environmental consequences - both positive and negative - of those actions. And second, it implied that this understanding is not enough. We need action on the part of everyone to address our conservation issues to "make waves."

In the Pritchard Lecture, Rick Cruse, Iowa State University professor and director of the Iowa Water Center, provided an overview of the global soil and water challenges agriculture faces to meet future demands of a rapidly growing population for food, feed, fiber, and fuel. He also spoke about sheet, rill, and ephemeral gully erosion patterns, which are evolving in the context of changing climate and weather. Clearly, the growing demand for agricultural production and effects of erosion on our soil resources send a strong signal that we cannot rely solely on agricultural

Iim Gulliford is executive director of the Soil and Water Conservation Society, Ankeny, lowa. production technology improvements to assure global food security. We must provide better protection and restoration of our soil resources.

The conference proximity to the Great Lakes and our theme of water impacts was central to the day two plenary session that featured Jamshed Merchant, Canada's Consul General in Minneapolis, Minnesota. Merchant described the challenge that Canada and the United States face to protect water quality in their shared border waters. The plenary response panel that followed Merchant's keynote discussed the need for programs and policy on both sides of the border to realize the protection that is necessary to ensure the drinking water and other ecosystem services so important to the economies and quality of life in both countries. It was startling that only one week later, on August 2, 2014, the mayor of Toledo, Ohio, announced that drinking water sourced from Lake Erie was not safe for drinking in that city. This event underscored the need to work together in preemptive action; we cannot wait for similar states of emergency to address the pollution of our waterways.

Exhibitors at the conference brought a wealth of information on products and services from both the public and private sector. Agency research, industry innovation, and public/private collaboration efforts were featured, and the interaction with conference participants was lively.The activities of the Soil Health Partnership were presented in a farmer panel that described how individual farmers, through their conservation learning experiences, can have an important impact on the management decisions of their neighbors.

Technical workshops, symposia, oral presentations, and posters provided an opportunity to learn from and connect with university, agency, and private sector researchers. The popularity of this year's new social science symposia highlighted the importance of understanding the physical and biological impacts of agricultural practices and the economic

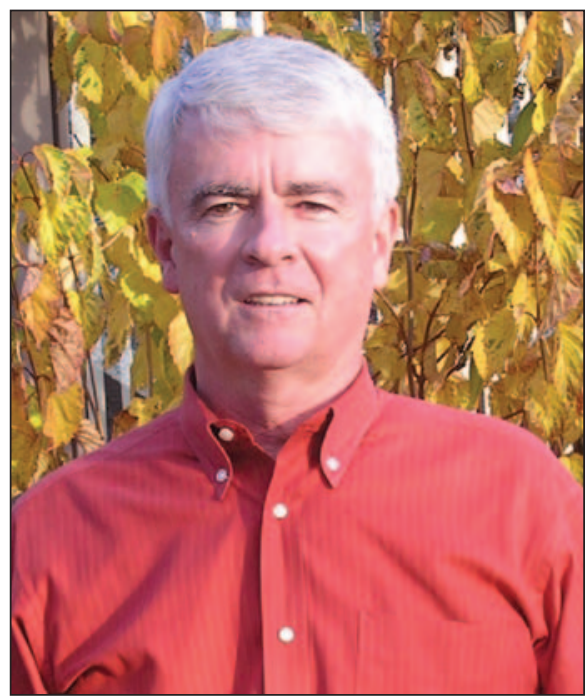

Jim Gulliford

and human aspects of agricultural decision making. The next generation of conservation programs and approaches was the subject of presentations and lively interaction.

Each year the Society acknowledges the contributions our members and colleagues are making in their conservation careers. This year, Mark Nearing received the Hugh Hammond Bennett Award in recognition of his career contribution to the development and enhancement of the Water Erosion Prediction Model (WEPP). The title of SWCS Fellow was conferred upon Alan Franzluebbers and Peter Kleinman for their exceptional service to the science and art of conservation and their career contributions to SWCS efforts. Additional awards for research, publication, chapter excellence, and individual contributions at national and local levels recognized the important impacts of many outstanding conservationists.

When I began this reflection on the conference, I mentioned the diversity of individuals and views that were in evidence. Participation by researchers, educators, farmers, administrators, and conservation professionals from public, private, and nongovernmental organizations brought a richness to presentations and attendee interaction that is a unique feature of the annual conference of the 
Soil and Water Conservation Society. For those of you who participated and contributed to the conference, we are grateful. I thank you for providing your experience and expressing your views. For those of you who could not join us in Lombard, videos of the conference plenaries and abstracts of presentations are available on the SWCS website. I encourage you to view them and recommend them to your colleagues.

Most of all, plan to join us next year, July 26-29, 2015, in Greensboro, North Carolina. Watch your email and the SWCS website for information on the conference and opportunities for submitting presentation abstracts. We hope to see you next year for another four days on the state of conservation and its future. 